BORDALLO, P.N.; PEREIRA, M.G.; AMARAL JÚNIOR, A.T.; GABRIEL, A.P.C. Análise dialélica de genótipos de milho doce e comum para caracteres agronômicos e proteína total. Horticultura Brasileira, Brasília, v.23, n.1, p.123-127, jan.-mar. 2005.

\title{
Análise dialélica de genótipos de milho doce e comum para caracteres agronômicos e proteína total
}

\author{
Patricia do N. Bordallo"1/; Messias G. Pereira ${ }^{2 /}$; Antônio T. do Amaral Júnior ${ }^{2 /}$; Ana Paula C. Gabriel ${ }^{2 /}$ \\ ${ }^{1 /}$ Iowa State University, Agronomy Department, Plant Transformation Facility, Ames, IA, 50011, USA;2/UENF-CCTA, Av. Alberto \\ Lamego, 2000, Parque Califórnia, 28013-600 Campos dos Goytacazes-RJ, Brasil; E-mail: bordallo@iastate.edu
}

\begin{abstract}
RESUMO
Com o objetivo de investigar a capacidade combinatória, bem como o efeito recíproco em dialelo envolvendo genótipos de milho doce e comum, avaliaram-se seis caracteres de interesse agronômico e industrial: altura de plantas, estande, porcentagem de espigas atacadas por pragas, teor de proteína no grão, peso médio de espiga sem palha e comprimento médio de espiga sem palha. Os valores dos quadrados médios referentes à capacidade geral de combinação $\left(\hat{G}_{i}\right)$ e capacidade específica de combinação $\left(\mathrm{S}_{\mathrm{ij}}\right)$ foram significativos para as características altura de planta, peso médio de espiga sem palha, comprimento médio de espiga sem palha e teor de proteína no grão, indicando a presença de efeitos gênicos aditivos e não aditivos no controle dos caracteres. Para peso médio de espiga sem palha e comprimento médio de espiga sem palha, as médias dos quadrados dos efeitos não diferiram, sugerindo a utilização de métodos intrapopulacionais ou interpopulacionais de melhoramento. Os genótipos Doce 13 e Sol da Manhã são os mais indicados para programas de melhoramento pelo comportamento dos valores de $\hat{\mathrm{G}}_{\mathrm{i}}$. Com base nos efeitos de $\mathrm{S}_{\mathrm{ij}}$, o melhor híbrido foi Doce 13 X Sol da Manhã.
\end{abstract}

Palavras-chave: Zea mays, capacidade combinatória, efeito recíproco.

\begin{abstract}
Diallel analysis of sweet and regular corn genotypes for agronomic characters and total protein content

The combining ability as well as reciprocal effect in diallel of sweet and regular corn genotypes was investigated for six agronomic and industrial characters: plant height, stand, percentage of ears attacked by insects, grain protein content, and average (mean) dehusked ear length and weight. General Combining Ability ( $\left.\hat{G}_{\mathrm{i}}\right)$ and Specific Combining Ability $\left(\mathrm{S}_{\mathrm{ij}}\right)$ mean square values were statistically significant when evaluating the following characters: plant height, average (mean) dehusked ear length and weight, and grain protein content, indicating that additive and non-additive genetic effects control these characters. There was no statistical difference regarding mean square effects of average (mean) dehusked ear length and weight characters suggesting the utilization of intra and interpopulational breeding methods. 'Doce 13' and 'Sol da Manhã' are among the most indicated genotypes for breeding programs due to observed trend of $\hat{G}_{\mathrm{i}}$ values. Based on specific combining ability estimates, the best hybrid originated from 'Doce 13' and 'Sol da Manhã' crossing.
\end{abstract}

Keywords: Zea mays, combining ability, reciprocal effect.

\section{(Recebido para publicação em 16 de abril de 2004 e aceito em 13 de setembro de 2004)}

$\mathrm{O}$ milho doce é um dos vegetais mais populares dos EUA e Canadá, sendo consumido in natura pela população e também utilizado pela indústria de enlatados (Tracy, 1994). O Brasil, como um dos maiores produtores de milho do mundo, possui, também, um grande potencial para a produção de milho doce. Entretanto, são poucos os híbridos de milho doce à disposição das indústrias de processamento existindo, portanto, a necessidade de se desenvolver novas combinações híbridas.

O melhoramento genético do milho doce pode ser resumido em duas formas de ações: introduzir o caráter doce (monogênico recessivo) de uma fonte genética qualquer em um material de endosperma normal comercialmente já utilizado, ou submeter um germoplasma doce a um programa de melhoramento de rotina (Parentoni et al., 1990).

Devido ao grande número de informações que a análise dialélica pode ofe- recer ao melhorista, esta é freqüentemente utilizada em programas de melhoramento de diversas culturas, sendo mais intensamente na cultura do milho (Hallauer e Miranda Filho, 1981; Amaral Júnior, 1996). Dentre as metodologias de análise dialélica, a proposta por Griffing (1956), permite obter as estimativas da capacidade geral de combinação $\left(\hat{G}_{\mathrm{i}}\right)$, além de proporcionar informações sobre a concentração de genes predominantemente aditivos em seus efeitos e são de grande utilidade na indicação de genitores a serem utilizados em programas de melhoramento intrapopulacional (Cruz e Regazzi, 2001). De acordo com Cruz e Regazzi (2001), uma baixa estimativa de $\hat{G}_{i}$, positiva ou negativa, indica que o valor da capacidade geral de combinação do genitor, obtida com base em suas populações híbridas, não difere muito da média geral da população dialélica.
Se os valores de $\hat{G}_{\mathrm{i}}$ são altos, positivos ou negativos, há indício de que o genitor em questão é muito superior ou inferior aos demais genitores do dialelo, com relação ao desempenho médio das progênies.

Os efeitos da capacidade específica de combinação $\left(\mathrm{S}_{\mathrm{ij}}\right)$, estimados como desvio do comportamento em relação ao que seria esperado com base na capacidade geral de combinação, são medidas dos efeitos gênicos não aditivos. São desejáveis aquelas combinações híbridas com estimativas de $\mathrm{S}_{\mathrm{ij}}$ mais favoráveis, que envolvam pelo menos um dos genitores que tenha apresentado o mais favorável efeito de $\hat{G}_{\mathrm{i}}$ (Cruz e Regazzi, 2001).

Os efeitos de $\mathrm{S}_{\mathrm{ij}}$ são úteis em determinar as melhores combinações híbridas mas não especificam qual dos genitores deve ser utilizado como parental feminino ou masculino no cruzamento. Para saber se um dado caráter 
é controlado somente por genes nucleares ou não, são utilizados os cruzamentos recíprocos, em que um determinado genitor é usado ora como parental masculino, ora como feminino.

Se a herança de um determinado caráter é controlada por genes nucleares, os resultados de um cruzamento e seu recíproco serão similares. Caso haja efeitos citoplasmáticos os resultados dos cruzamentos recíprocos serão diferentes, onde o fenótipo dos descendentes será influenciado pelo genitor feminino que contribuiu com o citoplasma. Dois mecanismos explicam esse tipo de herança: efeito materno, em que a herança é controlada por genes nucleares do parental feminino, independente dos genes doados pelo parental masculino; e herança extracromossômica, em que a herança é devido a genes localizados no citoplasma (principalmente mitocôndrias e cloroplastos) (Ramalho et al., 2001).

Os objetivos deste trabalho foram avaliar, por meio de cruzamentos dialélicos, as capacidades geral $\left(\hat{\mathrm{G}}_{\mathrm{i}}\right)$ e específica $\left(\mathrm{S}_{\mathrm{ij}}\right)$ de combinação, respectivamente, CGC e CEC, bem como o efeito recíproco de dois genótipos de milho doce e um de milho comum, com base em caracteres agronômicos e proteína total, com o intuito de desenvolver cultivares e, ou híbridos de milho doce adaptados às regiões norte e noroeste do estado do Rio de Janeiro.

\section{MATERIAIS E MÉTODOS}

Foram utilizados dois genótipos de milho doce, 'Doce 13' e 'Queen Anne', e um de milho comum, o 'Sol da Manhã', seus híbridos $\mathrm{F}_{1 \text { 's }}$ e os recíprocos. As sementes do 'Doce 13' foram provenientes da Universidade Federal de Viçosa, as sementes do 'Queen Anne' foram cedidas pelo Banco de Germoplasma da Embrapa Milho e Sorgo, enquanto as sementes da cultivar Sol da Manhã (BR 157 Nitroflint) foram cedidas pela PESAGRO-RIO, EE de Campos dos Goytacazes (RJ).

As características dos genótipos são descritas a seguir. 'Doce 13' possui o gene sul mutante, de porte médio (altura da planta $1,50 \mathrm{~m}$ e altura de espigas
0,84 m), espigas de forma cilíndrica com grãos de cor amarelo claro, ciclo normal e florescimento masculino aos $59 \mathrm{e}$ feminino aos 61 dias. 'Queen Anne' gene mutante não conhecido, de porte baixo (altura de plantas $0,80 \mathrm{~m}$ e altura de espigas $0,15 \mathrm{~m}$ ), espigas pequenas e cilíndricas com grãos de cor amareloclaros e florescimento masculino aos 50 e feminino aos 52 dias. 'Sol da Manhã' grãos de endosperma normal tipo duro, porte médio (altura de plantas 2,20 m e altura de espigas $1,20 \mathrm{~m}$ ), ciclo normal e florescimento masculino aos 65 e feminino aos 70 dias.

A semeadura foi realizada em Campos dos Goytacazes (RJ), em julho/agosto de 1999, em esquema de cruzamento dialélico entre os três genótipos, para a obtenção dos híbridos $F_{1 \mathrm{~s}}$ e seus recíprocos. Foram semeados 27 pares de fileiras, representando os 9 pares entre os genótipos, com 3 repetições. As fileiras foram espaçadas de $1 \mathrm{~m}$. Foram semeadas 3 sementes por cova com 0,5 $\mathrm{m}$ entre elas. Após 40 dias foram desbastadas, deixando-se uma planta por cova. A adubação consistiu de $700 \mathrm{~kg}$ $\mathrm{ha}^{-1}$ do formulado 4-14-8 (N- $\left.\mathrm{P}_{2} \mathrm{O}_{5}-\mathrm{K}_{2} \mathrm{O}\right)$ no plantio, e posteriores adubações nitrogenadas com $100 \mathrm{~kg} \mathrm{ha}^{-1}$ de $\mathrm{N}$ aos 30 e 45 dias após o plantio. As polinizações planta a planta foram feitas manualmente entre os pares de fileiras. As sementes foram posteriormente coletadas para a condução do experimento.

O ensaio experimental foi implementado no mesmo local, em março de 2000, em delineamento em blocos ao acaso, com quatro repetições. As parcelas foram constituídas de fileiras únicas de $5 \mathrm{~m}$ de comprimento, espaçadas de $1 \mathrm{~m}$ entre fileiras e $0,2 \mathrm{~m}$ entre plantas. A adubação de base e nitrogenada seguiram da mesma forma como descritas acima. Todos os experimentos foram conduzidos sob irrigação por aspersão.

Os caracteres avaliados (25 dias após o florescimento feminino) foram: 1) Altura média das plantas obtida do nível do solo até o nó de inserção do pendão; 2) Comprimento médio das espigas sem palha obtida pela medida de 5 espigas aleatórias de cada parcela com posterior cálculo da média do caráter por espiga; 3) Número de plantas por fileira (estande) obtido pela contagem das plantas de cada parcela na época da colheita; 4) Peso médio das espigas sem palha obtido pela pesagem de 5 espigas aleatórias de cada parcela com posterior cálculo da média do caráter por espiga; 5) Espigas com praga obtida pela contagem e posterior expressão em porcentagem do número de plantas ou espigas; 6) Teor de proteína determinado pelo método Kjeldahl, segundo Silva (1990). Para a análise da proteína as espigas foram colhidas aos 25 dias após florescimento, e levadas para estufa de circulação forçada a $60^{\circ} \mathrm{C}$. Quando atingiram peso constante, as espigas foram debulhadas e moídas em moinho com peneira de 30 mesh.

Todas as análises de variância e dialélicas, foram realizadas de acordo com o método 1, modelo 1, de Griffing (1956), utilizando o programa GENES (Cruz, 1997).

\section{RESULTADOS E DISCUSSÃO}

As somas dos quadrados para as médias dos tratamentos foram decompostas em capacidade geral (CGC) e específica de combinação (CEC) e efeito recíproco (E. Rec.), conforme o Método 1, Modelo 1, proposto por Griffing (1956). Os valores dos quadrados médios referentes à CGC e CEC foram significativos para as características altura de plantas, peso médio de espigas sem palha, comprimento médio de espigas sem palha, e proteína, indicando que os efeitos gênicos aditivos e não aditivos estão envolvidos no controle dos caracteres (Tabela 1).

Os efeitos de CEC, apesar de serem úteis na indicação das melhores combinações híbridas, não especificam qual dos genitores deverá ser utilizado como genitor masculino ou feminino no cruzamento eleito; para obter essa informação, utilizam-se os efeitos recíprocos (Cruz e Regazzi, 2001) Para este trabalho, apenas o caráter estande foi significativo para efeito recíproco (Tabela 1).

Em relação à média dos quadrados dos efeitos para o caráter altura de plantas, houve predominância dos efeitos gênicos aditivos, indicando que a estratégia de melhoramento mais adequada, 
Tabela 1. Estimativas dos quadrados médios da capacidade geral de combinação (CGC), da capacidade específica de combinação (CEC), do efeito recíproco (E. Rec) e do erro, e média dos quadrados dos efeitos para seis caracteres de milho, de acordo com o Método 1, Modelo 1, de Griffing. Campos dos Goytacazes, UENF, 2002.

\begin{tabular}{|c|c|c|c|c|c|c|c|}
\hline \multirow{2}{*}{ FV } & \multirow{2}{*}{ GL } & \multicolumn{6}{|c|}{ Quadrados médios $^{1}$} \\
\hline & & AP & ST & PESP & \%ECP & CESP & PTN \\
\hline CGC & 2 & $9344,07^{* *}$ & $134,37^{* *}$ & $0,0179^{* *}$ & $2550,52^{* *}$ & $102,615^{\star *}$ & $7,515^{\star}$ \\
\hline CEC & 3 & $1058,16^{* *}$ & $13,5 \mathrm{~ns}$ & $0,0034^{* *}$ & $562,69^{\text {ns }}$ & $20,826^{* *}$ & $10,538^{* *}$ \\
\hline E. Rec & 3 & $185,70^{\text {ns }}$ & $139,08^{* *}$ & $0,0003^{\text {ns }}$ & $260,08^{\text {ns }}$ & $0,89^{\text {ns }}$ & $3,833^{\text {ns }}$ \\
\hline Erro & 24 & 84,51 & 9,96 & 0,0005 & 367,30 & 1,5598 & 1,4066 \\
\hline CV (\%) & & 6,04 & 18,66 & 20,37 & 34,09 & 7,88 & 8,07 \\
\hline Média dos quadrados dos efeitos & & AP & ST & PESP & NECP & CESP & PTN \\
\hline$(1 / 2) \mathrm{Sgi}^{2}$ & & 385,81 & 5,183 & 0,0007 & 90,967 & 4,2106 & 0,254 \\
\hline$(1 / 3) S_{s i j}{ }^{2}$ & & 243,41 & 0,884 & 0,0007 & 48,846 & 4,8167 & 2,283 \\
\hline$(1 / 3) \mathrm{SRij}^{2}$ & & 12,64 & 16,1403 & $-0,00002$ & $-13,402$ & $-0,083$ & 0,303 \\
\hline $\mathrm{s}^{2} \mathrm{e}$ & & 84,51 & 9,96 & 0,0005 & 367,30 & 1,5598 & 1,4066 \\
\hline
\end{tabular}

** = Significativo no nível de $1 \%$ pelo teste $\mathrm{F} ; *$ = Significativo no nível de $5 \%$ pelo teste $\mathrm{F} ; \mathrm{e}^{1}=\mathrm{AP}$ : altura de plantas; ST: estande; PESP: peso médio de espigas sem palha; \%ECP: percentual de espigas com pragas; CESP: comprimento médio de espigas sem palha; e PTN: proteína.

nesse caso, é a exploração desses efeitos por métodos intrapopulacionais, como seleção massal, seleção recorrente de famílias de meios irmãos, de irmãos completos e de famílias endogâmicas (Tabela 1). Para peso médio de espigas sem palha e comprimento médio de espigas sem palha a média dos quadrados dos efeitos praticamente não diferiu sugerindo que tanto métodos intrapopulacionais quanto interpopulacionais, como seleção recorrente recíproca de famílias de meios irmãos e de irmãos completos podem ser utilizados, neste último caso explorando a heterose. Apenas o valor do quadrado médio para CGC foi significativo para percentual de espigas com pragas, indicando maior importância dos efeitos gênicos aditivos no controle do caráter, o que sugere o uso de métodos intrapopulacionais de melhoramento para ganhos futuros. Já o caráter estande foi significativo para CGC e efeito recíproco, indicando que além de efeitos gênicos aditivos pode-se explorar a heterose com base na médias dos quadrados do efeito recíproco, pois existe um genitor contribuindo com sua herança materna no controle do caráter.

Com relação a CGC $\left(\hat{G}_{i}\right)$ para o caráter altura de plantas (Tabela 2) constata-se que os genótipos Doce 13 e Sol da Manhã possuem valores positivos de $\hat{G}_{i}$, indicando tendência de aumento na contribuição gênica para altura de plantas nos cruzamentos em que participam. 'Doce 13' também apresentou maior

Tabela 2. Estimativas dos efeitos da capacidade geral de combinação ( $\left.\hat{G}^{i}\right)$ para seis caracteres de três genótipos de milho e desvios-padrão (DP) dos efeitos dos parentais. Campos dos Goytacazes, UENF, 2002.

\begin{tabular}{lrrrrrr}
\hline \multirow{2}{*}{ Genótipos } & \multicolumn{6}{c}{ Efeitos $^{1}$} \\
\cline { 2 - 7 } & \multicolumn{1}{c}{ AP } & \multicolumn{1}{c}{ ST } & PESP & \multicolumn{1}{c}{ \%ECP } & \multicolumn{1}{c}{ CESP } & PTN \\
\hline Doce 13 & 14,0010 & 1,6660 & 0,0040 & $-3,2350$ & 0,9750 & 0,4050 \\
Queen Anne & $-22,5600$ & $-2,7080$ & $-0,0290$ & 11,5380 & $-2,3750$ & 0,2320 \\
Sol da Manhã & 8,5500 & 1,0410 & 0,0240 & $-8,3030$ & 1,4000 & $-0,6380$ \\
DP (Gi-Gj) & 2,6537 & 0,9110 & 0,0064 & 5,5320 & 0,3605 & 0,3420 \\
\hline
\end{tabular}

1 = AP: altura de plantas; ST: estande; PESP: peso médio de espigas sem palha; \%ECP: percentual de espigas com pragas; CESP: comprimento médio de espigas sem palha; e PTN: proteína.

Tabela 3. Estimativa dos efeitos da capacidade específica de combinação $\left(\mathrm{s}_{\mathrm{ii}}\right.$ e $\left.\mathrm{s}_{\mathrm{ij}}\right)$ para seis caracteres de milho e desvios-padrão (DP) dos efeitos de dois $\mathrm{F}_{1} \mathrm{~s}$ com e sem parental comum e entre dois parentais. Campos dos Goytacazes, UENF, 2002.

\begin{tabular}{|c|c|c|c|c|c|c|}
\hline \multirow{2}{*}{$\begin{array}{l}\text { Efeitos } \\
\left(s_{\mathrm{ii}} \text { e } s_{\mathrm{ij}}\right)^{1}\end{array}$} & \multicolumn{6}{|c|}{ Caracteres Avaliados $^{2}$} \\
\hline & AP & ST & PESP & \%ECP & CESP & PTN \\
\hline $1 \times 1$ & $-16,3105$ & $-0,7500$ & $-0,0300$ & 1,6800 & $-1,9330$ & 0,4197 \\
\hline $1 \times 2$ & 2,8282 & $-0,7500$ & 0,0170 & $-1,3400$ & 1,3660 & $-1,0070$ \\
\hline $1 \times 3$ & 13,4822 & 1,5000 & 0,0130 & $-0,3300$ & 0,5660 & 0,5870 \\
\hline $2 \times 2$ & $-1,2398$ & 1,5000 & $-0,0210$ & $-9,2400$ & $-2,1330$ & 1,8630 \\
\hline $2 \times 3$ & $-1,5883$ & $-0,7500$ & 0,0043 & 10,5950 & 0,7660 & $-0,8550$ \\
\hline $3 \times 3$ & $-11,8938$ & $-0,7500$ & $-0,0170$ & $-10,2630$ & $-1,3330$ & 0,2670 \\
\hline $2 \times 1$ & $-3,8950$ & 3,1250 & 0,0030 & 6,8750 & 0,0500 & $-0,2000$ \\
\hline $3 \times 1$ & $-3,2925$ & 0,3750 & 0,0005 & 7,0900 & 0,0250 & 0,2010 \\
\hline $3 \times 2$ & $-6,605$ & $-6,5000$ & $-0,0110$ & 0,0000 & $-0,5750$ & 1,1650 \\
\hline DP (sii - $\left.s_{j j}\right)$ & 3,7529 & 1,2884 & 0,0091 & 7,8242 & 0,5098 & 0,4841 \\
\hline DP (sij - sik) & 3,7529 & 1,2884 & 0,0091 & 7,8242 & 0,5098 & 0,4841 \\
\hline DP (sij - skl) & 2,6537 & 0,9110 & 0,0064 & 5,5325 & 0,3605 & 0,3423 \\
\hline
\end{tabular}

$1=1$ : Doce 13; 2: Queen Anne; e 3: Sol da Manhã ${ }^{2}=$ AP: altura de plantas (cm); ST: estande; PESP: peso médio de espigas sem palha (kg); \%ECP: percentual de espigas com pragas; CESP: comprimento médio de espigas sem palha $(\mathrm{cm})$; e PTN: proteína (\%).

valor de $\hat{\mathrm{G}}_{\mathrm{i}}$ no trabalho desenvolvido por Scapim (1994) quando em combinação com outros seis genótipos de milho doce. O genótipo Queen Anne mostrou alto valor negativo, contribuindo, assim, para reduzir a altura das plantas nos 
Tabela 4. Análise da correlação de Pearson entre seis caracteres agronômicos e bioquímicos de milho doce (Zea mays) em um cruzamento dialélico entre os genitores Doce 13, Queen Anne e Sol da Manhã pelo Método 1, de Griffing. Campos dos Goytacazes, UENF, 2002.

\begin{tabular}{lcllllr}
\hline Var $^{1}$ & AP & ST & PESP & \%ECP & CESP & PTN \\
\hline AP & 1,00 & $0,67^{*}$ & $0,84^{*}$ & $-0,71^{*}$ & $0,90^{*}$ & $-0,16$ \\
ST & & 1,00 & 0,58 & $-0,42$ & 0,57 & $-0,26$ \\
PESP & & & 1,00 & $-0,62$ & $0,96^{*}$ & $-0,57$ \\
\%ECP & & & & 1,00 & $-0,59$ & 0,03 \\
CESP & & & & & 1,00 & $-0,52$ \\
PTN & & & & & 1,00 \\
\hline
\end{tabular}

${ }^{1}=$ AP: altura de plantas $(\mathrm{cm})$; ST: estande; PESP: peso médio de espigas sem palha $(\mathrm{kg})$; \%ECP: percentual de espigas com pragas; CESP: comprimento médio de espigas sem palha (cm); e PTN: proteína (\%).

cruzamentos em que participa (Tabela 3). A forma de produção e a sua integração com as outras atividades desenvolvidas pelo produtor deve ser avaliada, particularmente no que se refere à altura ideal das plantas. Em áreas irrigadas é comum o contrato com indústrias enlatadoras, que por sua vez seguem cronograma rígido de recebimento de matéria-prima. Isso exige um uso intenso da área plantada onde são realizados diversos plantios consecutivos, dando preferência a cultivares precoces e de porte reduzido de tal forma que a incorporação de restos culturais não prejudique o plantio posterior e que se obtenha o maior número de colheitas por ano e por local. Neste caso, os híbridos provenientes de cruzamentos entre 'Queen Anne' e 'Doce 13', e entre 'Queen Anne' e 'Sol da Manhã’ favoreceria a diminuição da altura das plantas. Quando se pretende utilizar os restos culturais na alimentação de bovinos, deve-se optar por cultivares que produzam mais massa, em geral plantas mais altas e mais tardias (Parentoni et al., 1990).

Considerando o caráter estande (Tabela 2) os genótipos Doce 13 e Sol da Manhã têm os maiores valores de $\hat{\mathrm{G}}_{\mathrm{i}}$ (1,666 e 1,041, respectivamente) contribuindo para número maior de plantas por parcela. Por sua vez, 'Queen Anne' teve o pior desempenho para essa característica haja vista a expressão de valor negativo para $\hat{\mathrm{G}}_{\mathrm{i}}$, com magnitude de -2,708. Isso denota que 'Queen Anne' contribui para diminuir o estande nos cruzamentos em que participa, sobretudo se utilizado como genitor feminino, em decorrência da significância do efeito recíproco para estande (Tabela 1) e por revelar, em sua quase totalidade, valores negativos para estande em cruzamentos em que participou como genitor feminino (Tabela 3).

Há que se destacar que o estande final ou número de plantas por fileira está diretamente relacionado com o potencial de germinação do milho doce, que é consabido ter baixo teor de amido no endosperma em face dos alelos mutantes alterarem a rota metabólica da formação do amido, favorecendo o acúmulo de açúcares. Enquanto o milho comum tem em média $71,5 \%$ de amido no grão inteiro (Tosello, 1978), o milho doce tem 22,9\% (para 'Doce-de-Ouro') (Pereira, 1987).

Tanto o caráter peso de espiga quanto comprimento de espiga sem palha tiveram comportamento similar na análise dos efeitos de CGC, sendo que o genótipo Sol da Manhã contribuiu positivamente quando em combinações híbridas para aumentar o peso e o comprimento das espigas sem palha. Teixeira et al. (2001) e Parentoni et al. (1991) também encontraram significância para CGC e CEC avaliando peso total de espigas sem palha, o que mostra a existência de variabilidade tanto para efeitos gênicos aditivos quanto não aditivos. Considerando-se que a média dos quadrados dos efeitos gênicos aditivos e não-aditivos foram equivalentes, com base no valor de 0,0007 (Tabela 1), isso indica que métodos intrapopulacionais e interpopulacionais poderão ser utilizados na melhoria do caráter, o que está em concordância com os resultados encontrados por Parentoni et al. (1991), Teixeira et al. (2001) e Scapim (1994).

$\mathrm{O}$ ataque da lagarta das espigas (Heliothis zea), apesar das freqüentes pulverizações com pesticidas, foi inten- so, variando de 59,3 a $100 \%$ das espigas atacadas. O resultados das estimativas do efeito de $\hat{G}_{\mathrm{i}}$ para percentual de espigas com pragas indica que o genótipo Sol da Manhã é o mais resistente ao ataque de pragas, provavelmente, por ser um milho de endosperma amiláceo, menos atrativo que o endosperma doce de 'Queen Anne' e 'Doce 13'. O maior valor de $\hat{G}_{\mathrm{i}}$ para 'Queen Anne' (Tabela 2), indica não se tratar de um genótipo interessante quando o objetivo do programa de melhoramento for aumentar a resistência ao ataque da lagarta das espigas. $\mathrm{O}$ genitor Doce 13 também revelou valor negativo de $\hat{\mathrm{G}}$, todavia, o ataque também foi severo, diferente do encontrado por Scapim (1994), que cita a cultivar como medianamente resistente em experimentos na Zona da Mata Mineira.

Pelas estimativas dos efeitos de $\hat{G}_{\mathrm{i}}$ para teor de proteína (Tabela 2), verifica-se que 'Doce 13' é o genitor que promove maiores ganhos genéticos no incremento do caráter naqueles cruzamentos de que participa, seguido por 'Queen Anne'. Destaca-se que o teor de proteína foi superior para os dois genótipos do tipo doce, sendo $15,1 \%$ para 'Doce 13 ' e 16,2\% para 'Queen Anne', cujos percentuais podem ser considerados elevados, se comparados com os teores encontrados no milho comum, que variam de 8 a $13 \%$ de proteína bruta (Andrigueto, 1981). Os teores encontrados permitem destacar esses genótipos como alimentos altamente protéicos, mesmo não sendo de alta qualidade como os milhos QPM ('Quality Protein Maize'), devido à deficiência de lisina e triptofano (Andrigueto, 1981; Parentoni et al., 1991).

Para altura de plantas, todos os valores de $\mathrm{S}_{\mathrm{ii}}$ foram negativos, o que indica ocorrência de desvios de dominância positivos (Tabela 3). A maior magnitude negativa para $\mathrm{S}_{\mathrm{ii}}$ foi revelada pelo genitor Doce 13, com valor de -16,3105, o que pressupõe contribuição de efeito heterótico positivo nos seus híbridos. $\mathrm{O}$ maior valor de $\mathrm{S}_{\mathrm{ij}}$ foi encontrado para a combinação 'Doce 13' x 'Sol da Manhã' $(13,4822)$; por conseguinte, 'Doce 13' x ' Sol da Manhã’ é um híbrido promissor. 'Doce 13' em cruzamento com 'Queen Anne' revelou valor de $\mathrm{S}_{\mathrm{ij}}$ não 
tão elevado, porém, positivo (2,8282), o que indica um ganho no caráter para 'Queen Anne'. Houve correlação positiva entre altura de plantas e peso médio e comprimento médio das espigas (Tabela 4), indicando que seleção para plantas altas implicará em espigas maiores e mais pesadas, o que está de acordo com o resultado encontrado por Lemos et al. (1999).

As estimativas dos efeitos da CEC e os desvios-padrão indicam que os desvios de dominância são positivos, isto é, os genes dominantes contribuem para aumentar a expressão do caráter peso médio de espiga sem palha. Contudo, os valores de $\mathrm{S}_{\mathrm{ii}}$ estão próximos de zero, indicando que a heterose presente nos híbridos também será zero ou próximo deste. Os maiores efeitos, em ordem decrescente, foram manifestados nos híbridos 'Doce 13' x 'Queen Anne' (0,017), 'Doce 13' x 'Sol da Manhã' $(0,013)$ e 'Queen Anne' x 'Sol da Manhã' $(0,0043)$, em que pelo menos um dos genitores tinha valor positivo de $\hat{\mathrm{G}}_{\mathrm{i}}$. Para comprimento médio das espigas sem palha, os desvios de dominância também são positivos, como indicam os valores de $\mathrm{S}_{\mathrm{ii}}$. Os maiores efeitos foram encontrados nas combinações híbridas 'Doce 13' x 'Queen Anne' (1,366), 'Queen Anne' x 'Sol da Manhã' $(0,766)$ e 'Doce 13' x 'Sol da Manhã' $(0,566)$, sendo que para as duas primeiras combinações pelo menos um dos genitores obteve valor positivo de $\hat{\mathrm{G}}_{\mathrm{i}}$. Os genitores Doce 13 e Sol da Manhã quando cruzados com 'Queen Anne' promoveram um incremento no comprimento da espiga, uma vez que 'Queen Anne é um genótipo não adaptado e que apresenta espigas pequenas, com média inferior a $10 \mathrm{~cm}$ de comprimento.

As estimativas da CEC para teor de proteína mostram que os desvios de dominância são negativos; desta forma, os genes dominantes não contribuem para aumentar a expressão do caráter. $\mathrm{O}$ maior efeito de $\mathrm{S}_{\mathrm{ij}}$ foi encontrado para o híbrido Doce 13 x Sol da Manhã $(0,587)$, haja vista que o genitor Doce 13 favorece o aumento do teor de proteína justamente por apresentar o maior valor positivo de $\hat{\mathrm{G}}_{\mathrm{i}}$ (Tabela 2).

Há que se destacar que a análise de variância para estande não revelou significância para CEC, mas a estatística $\mathrm{F}$ foi altamente significativa para efeito recíproco (Tabela 1). Neste caso, quando o genitor Sol da Manhã foi cruzado com pólen de 'Queen Anne', o valor de $R_{i j}$ foi o menor $\left(R_{i j}=-6,5\right)$ para estande, decorrente de 'Queen Anne' influenciar negativamente a performance de 'Sol da Manhã'. O mesmo foi observado no híbrido Queen Anne x Doce 13 $\left(R_{i j}=-0,75\right)$.

\section{AGRADECIMENTOS}

Os autores agradecem à EE da PESAGRO-RIO de Campos dos Goytacazes e ao Colégio Agrícola Antônio Sarlo pela oportunidade de implementar os experimentos de campo, bem como ao técnico agrícola Geraldo Francisco de Carvalho pelo auxílio em todas as etapas do experimento. Finalmente agradecem à FENORTE pelo auxílio financeiro para suporte das pesquisas.

\section{LITERATURA CITADA}

AMARAL JUNIOR, A.T. Análise dialélica de betacaroteno, vitamina $C$, sólidos solúveis e produção e variabilidade em cultivares de tomateiro (Lycopersicon esculentum MILL) via marcadores RAPD. em Genética e Melhoramento. 1996. 198 f. (Tese doutorado) - UFV, Viçosa.

ANDRIGUETO, J.M. Nutrição Animal, v.1, São Paulo: Nobel, 1981. 395 p.
Cruz, C.D.; Regazzi, A.J. Modelos biométricos aplicados ao melhoramento genético. 2. ed. Viçosa: UFV, 2001. 390 p.

CRUZ, C.D. (1997) Programa GENES-Aplicativo computacional em genética e estatística. Viçosa: Editora UFV, 1997. 394 p.

GOLDMAN, I.L.; TRACY, W.F. Kernel protein concentration in sugary-1 and shrunken-2 sweet corn. HortScience, v.29, n.3, p.209-210, 1994.

GRIFFING, B. Concept of general and specific combining ability in relation to diallel crossing systems. Australian Journal of Biological Science. v.9, p.463-493, 1956.

HALLAUER, A.R.; MIRANDA FILHO, J.B. Quantitative genetics in maize breeding. Ames: Iowa State University Press, 1981. 468 p.

LEMOS, M.A.; GAMA, E.E.G.; PARENTONI, S.N.; OLIVEIRA, A.C.; REIFSHNEIDER, F.J.B.; SANTOS, J.P.O.; TABOSA, J.N. Capacidades geral e específica de combinação em híbridos simples de milho doce. Ciência e Agrotecnologia, v.23, n.1, p.48-56, 1999.

PARENTONI, S.N.; GAMA, E.E.G.; MAGNAVACA, R.; REIFSCHNEIDER, F.J.B.; BOAS, G.L.V. Milho doce. Informe Agropecuário, Belo Horizonte, v.14, n.165, p.17-22, 1990.

PARENTONI, S.N.; GAMA, E.E.G.; REIFSCHNEIDER, F.J.B.; GUIMARÃES, P.E.O. Avaliação da capacidade combinatória de dez linhagens de milho doce. Horticultura Brasileira, Brasília, v.9, n.2, p.71-73, 1991.

PEREIRA, A.S. Composição, avaliação organoleptica e padrão de qualidade de cultivares de milho-doce. Horticultura Brasileira, Brasília, v.5, n.2, p.22-24, 1987.

RAMALHO, M.A.P.; SANTOS, J.B.; PINTO, C.B. Genética na Agropecuária. 2.ed. Lavras: Editora UFLA, 2001. 472 p.

SCAPIM, C.A. Cruzamentos dialélicos entre sete variedades de milho doce (Zea mays L.) e correlações entre caracteres agronômicos. 1994. $96 \mathrm{f}$. (Tese mestrado) - : UFV, Viçosa.

SILVA, D.J. Análise de Alimentos (métodos químicos e biológicos). Viçosa: UFV, 1990. 166 p. TEIXEIRA, F.F.; SOUZA, I.R.P.; GAMA, E.E.G.; PACHECO, C.A.P.; PARENTONI, S.N.; SANTOS, M.X.; MEIRELLES, W.F. Avaliação da capacidade de combinação entre linhagens de milho doce. Ciência e Agrotecnologia, v.25, n.3, p.438-488, 2001.

TOSELLO, G.A. (1978) Milhos especiais e seu valor nutritivo. In: PATERNIANI, E. ed. Melhoramento e produção do milho no Brasil. Piracicaba: ESALQ, 1978. p.310-332.

TRACY, W.F. Sweet Corn. In: Specialtry Corns. CRC Press, p.147-187. 